\title{
CAPTIVE BREEDING OF THE INDIAN STAR TORTOISE (GEOCHELONE ELEGANS)
}

\author{
Raju Vyas \\ Sayaji Baug Zoo, Vadodara, Gujarat 390018, India \\ Email: razoovyas@hotmail.com
}

\begin{abstract}
This paper is the result of a seven year study on a captive group of two males and three females of Indian Star Tortoise (Geochelone elegans). Two-hundred-and-three eggs were produced in 39 clutches. One-hundred-and-thirty-one hatchlings were successfully hatched in an average of 198 days. A positive correlation was noticed between egg size and hatchling size.
\end{abstract}

\section{KeYWORDS \\ Breeding, captivity, Geochelone elegans, tortoise, testudines, western population,}

Geochelone elegans (Indian Star Tortoise, IST) is one of the most popular tortoise species in the world of zoos, private hobbyists and pet collectors with enormous demand nationally and internationally. In the last few years a large number of ISTs have been illegally collected from their natural habitat as well as private collections and smuggled out of India.

This species is widely distributed in dry, arid and deciduous forest area of the Indian subcontinent from Thar Desert of Pakistan to India (Rajasthan, Gujarat, Karnataka, Andhra Pradesh, Orrisa, Tamil Nadu, Madhya Pradesh and Kerala) and further south in Sri Lanka (Das, 1995; de Silva, 2003). The mainland population is recognised by two separate populations (western and southern), on the bases of morphomatric characters and colour form (Frazier, 1992). The western population occurs from Thar Desert, Pakistan to Rajasthan, Gujarat and western Madhya Pradesh, while the southern population is distributed from Orrisa, Andhra Pradesh, Karnataka, Tamil Nadu and Kerala. Both these population appear to be separated by Vindhya and Satpura mountains (see Choudhury \& Bhupathy, 1993).

The reproduction and captive management of IST has been described earlier by Deraniyagala (1939), Jayakar and Spurway (1964, 1966), Kirsche (1976), Das, (1991), Biswas and Acharjyo (1984), Whelan and Coakley (1982, 1985), Whitaker (1974), Thulsi Rao and Subba Rao (1990), and Jagannadha Rao (1995). Das (1995) and Daniel (2002) reviewed and summarized aspects of breeding biology of the species, particularly sexual maturity, egg and clutch size, incubation period and size of hatchlings. Preliminary result of captive breeding program has been published by Grigus (1998) and more recently by de Silva (2003) of Sri Lanka animals.

The present paper is based on observations between 1990 1997 on a captive population of ISTs at Sayaji Baug Zoo, Vadodara, Gujarat, India to gather information on captive management and breeding biology of the species. This experience is discussed and documented here with the understanding of the husbandry and management problems in Indian condition that may be helpful further in its management in captivity and also in conservation of the species.

\section{Materials and Methods}

The study was carried out at Sayaji Baug Zoo, Vadodara, Gujarat, India $\left(22^{0} 19^{\prime} 00^{\prime N} \mathrm{~N} \& 73^{\circ} 13^{\prime} \mathrm{E}\right)$ for seven years from 1990 to 1997 of a small population of ISTs maintained there for display and educational purposes.

Five healthy adult ISTs (Table 1) were selected for the study and kept separately (along with an avian species Pavo cristatus) in a breeding cage with 1:1.5 sex ratio ( 2 males and 3 females). This breeding stock was selected from the captive population of the zoo and as per the stock record register, all the ISTs were procured from the surroundings of Vadodara and Panchmahal district of Gujarat State, India.

Each of the specimens was individually identified by its external natural identification and colour code (nail polish) marks. The breeding season of the species considered here is from June to May. Nests were opened carefully on the second or third day of egg laying and nests as well as eggs were measured and marked for further records. Also each of the located nest was given a number and covered with piece of wire mesh (for prevention from further damage by other female(s).

All the data was recorded regarding courtship, nesting and daily activity patterns. The eggs and hatchlings were measured with dial-vernier callipers $(0.2 \mathrm{~mm})$ and weighed with 'Pesola Precision scale' and spring balance. The nest size, measurements of inner chamber and depth of buried eggs were recorded. The hatchlings were measured after a day of incubation because most new hatchlings have folded plastron

Table 1. Body measurements of the breeding stock of Indian Star Tortoise (G. elegans) at Sayaji Baug Zoo, Vadodara, Gujarat

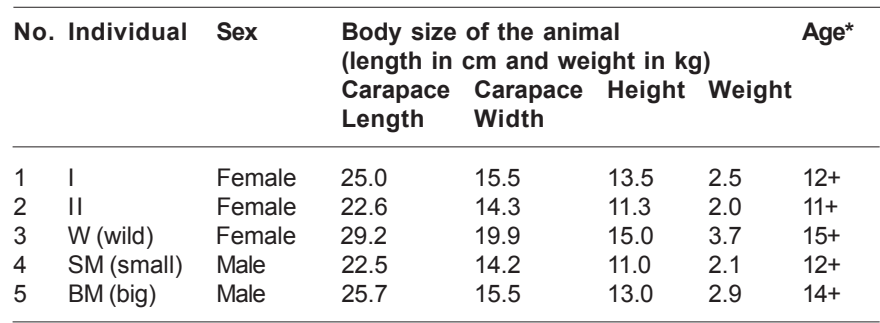

${ }^{*}$ Approximately on basis of counting of growth ring of carapace. $\mathrm{SM}$ - Small Male; BM - Bigger Male

(C) Zoo Outreach Organisation; www.zoosprint.org Manuscript 1186; Received 22 April 2004; Revised received 10 December 2004; Finally accepted 24 March 2005; Date of publication 21 April 2005 
and marginals, and protruding yolk sac. Environmental factors such as temperature, photoperiod and humidity were recorded.

\section{Breeding enclosure}

The floor space of the breeding enclosure measured $178 \mathrm{~m}^{2}$. It was a half-rounded cage covered with $20 \times 20 \mathrm{~mm}$ chain-link wire mesh with earthen floor. The top of the enclosure was covered with wire mesh for protection against predators. Half of the top was covered with climbers for shade. A flat platform was provided for feeds and a small water container for drinking water at the ground level. The soil of the enclosure was mixed with $50 \%$ sand to prevent it from becoming too hard.

\section{Feeds}

Ad libitum feed was provided each morning. This included vegetables (Dhania Coriandrum sativum, Dudhi Lagenaria leucontha, Palakh Spenacia oleracea) and boiled eggs were served in small pieces, cereals, grain and sprouted pulses (Chana Cicer arieium, Math Vigna aconitifolia and Makai Zea mays) leaves and flowers of Lachko (Medicago sativum). Leaves of Thor (Euphorbia nivulia) were also given occasionally.

\section{Results}

\section{Courtship and mating season}

Courtship and mating behaviours were observed for 10 months between June to March, i.e., monsoon and winter. Males were active as soon as the rains started in middle of June and gradually courtship and mating activity ceased by the end of March.

During mating season, males constantly walked behind the females to copulate. When the female stopped walking, the male smelt the female constantly and moved towards her posterior. If the female was in a receptive mood she stopped walking, otherwise she walked away in the cage avoiding the male. Non-receptive females have been observed to push the male from the side and 'turn turtle'.

Totally 208 successful matings were observed during the different times of the day throughout the study. More numbers of mating attempts and longer duration of mating was observed during monsoons. More number of successful matings were observed in the bigger male (Fig. 1). Higher numbers of matings were recorded during mornings and evenings (Fig. 2).

\section{Nesting season}

Nesting season of the species was from October to March which peaked between October and December. Nesting decreased during March and further from winter to summer.

Females dug two to three trial nest pits prior to nesting. During the seven years of study, three females, with annual rate of 1.85 nest/female, prepared a total of 39 nests. Highest number of nine nests were recorded during 1993-94 and lowest number of three during 1990-91 (Appendix 1).

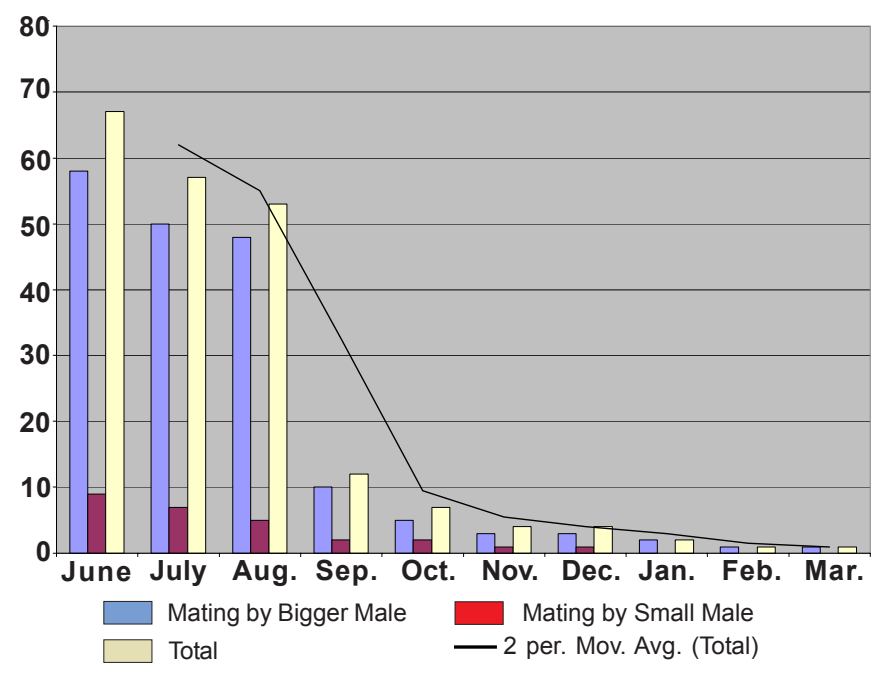

Figure 1. Month-wise numbers of mating observed in G. elegans during the study

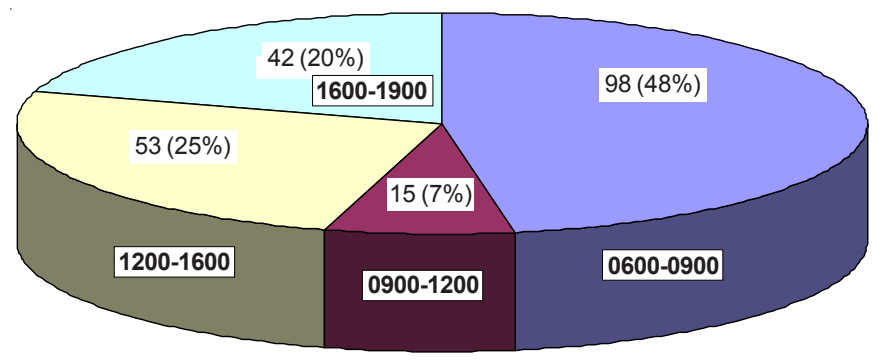

Figure 2. Diurnal pattern of mating observed in G. elegans

In terms of nesting performance, female FI and FII had higher number of nests (16 and 15 respectively), while poor performance was noted in the case of female FIII with eight nests.

\section{Inter-nesting period}

The intervals between two successive clutches varied from 25 to 385 days with an average of 176.6 days. Inter-nesting period between two clutches $\left(3^{\text {rd }}\right.$ clutch of previous season and $1^{\text {st }}$ clutch of subsequent season) of different seasons were always longer $(\mathrm{x}=314$ days; $\mathrm{n}=18)$ than between two successive clutches ( $1^{\text {st }}$ and $2^{\text {nd }}$ clutch, or $2^{\text {nd }}$ and $3^{\text {rd }}$ clutch). But internesting period between $3^{\text {rd }}$ and $4^{\text {th }}$ successive clutches was only five days than the inter-nesting period of $2^{\text {nd }}$ and $3^{\text {rd }}$ clutches (Table 2).

\section{Clutch and egg size}

The results of 39 clutches recorded show an average of 1.85 clutch per year. The clutch size recorded was 2 to 10 eggs with an average of 5.13 eggs. Average individual clutch size 5.87, 4.66 and 4.87 eggs/nest was recorded in FI, FII and FIII females, respectively.

Of the 12 times when multiple clutches were recorded; six belonged to female FI, five to FII and one to FIII. Two females (FI and FII) laid four clutches during a breeding season (1993- 
Table 2. Comparative statements on periods between two subsequent breeding seasons and inter-clutches (period in day).

\begin{tabular}{|c|c|c|c|c|c|c|}
\hline \multirow[b]{2}{*}{$\begin{array}{l}\text { Breeding } \\
\text { years }\end{array}$} & \multicolumn{2}{|c|}{ Female I } & \multicolumn{2}{|c|}{ Female II } & \multicolumn{2}{|c|}{ Female III } \\
\hline & $\begin{array}{l}\text { Periods between } \\
\text { subsequent } \\
\text { breeding seasons }\end{array}$ & $\begin{array}{l}\text { Periods between } \\
\text { two successive } \\
\text { clutches }+2^{\text {nd }}+3^{\text {rd }}+4^{\text {th }}\end{array}$ & $\begin{array}{l}\text { Periods between } \\
\text { of Sub-sequent } \\
\text { breeding seasons }\end{array}$ & $\begin{array}{l}\text { Periods of between } \\
\text { two successive } \\
\text { clutches }+2^{\text {nd }}+3^{\text {rd }}+4^{\text {th }}\end{array}$ & $\begin{array}{l}\text { Periods between } \\
\text { subsequent } \\
\text { breeding seasons }\end{array}$ & $\begin{array}{l}\text { Periods between } \\
\text { two successive } \\
\text { clutches }+2^{\text {nd }}+3^{\text {rd }}+4^{\text {th }}\end{array}$ \\
\hline $1990-91$ & -- & - & - & - & -- & -- \\
\hline $1991-92$ & 306 & 65 & 273 & 93 & 299 & \\
\hline $1992-93$ & 316 & 43 & 278 & 40 & 385 & 52 \\
\hline $1993-94$ & 313 & $25+37+40$ & 325 & $29+35+40$ & 391 & \\
\hline 1994-95 & 241 & $57+35$ & 227 & $30+30$ & 257 & \\
\hline $1995-96$ & 272 & 74 & 302 & 93 & 369 & \\
\hline $1996-97$ & 358 & 43 & 378 & & 372 & \\
\hline Average & 301 & $56.3+36+40$ & 297 & $57+32.5+40$ & 345.5 & 52 \\
\hline (Range) & $(241-358)$ & $(43-74)+(35-36)+(40)$ & $(227-378)$ & $(29-93)+(30-35)+(40)$ & $(257-391)$ & \\
\hline
\end{tabular}

94), while all three females laid two clutches each during 199293.

The average egg size was $41.4 \times 34.4 \mathrm{~mm}$ and weight $27.9 \mathrm{~g}(\mathrm{n}=$ 203). The largest egg size was $48.2 \times 41.3 \mathrm{~mm}$ and $47.5 \mathrm{~g}$ (FIII: 1993-94) and smallest egg size was $36.1 \times 33.3 \mathrm{~mm}$ and least weight of $22 \mathrm{~g}$ (FI: 1994-95).

The egg size and weight were more for the $1^{\text {st }}$ clutch than $2^{\text {nd }}$ and $3^{\text {rd }}$ clutches of a female. Average egg size and weight gradually decreased when female laid multiples clutches in a breeding season, except in the $4^{\text {th }}$ clutch (Table 3). Most eggs were ellipsoidal in shape and with white hard, brittle shell. Over all, larger sized eggs were laid by FIII female and smaller sized eggs were laid by FI female.

\section{Incubation period and hatchling success}

The incubation period recorded varied from 107 to 257 days with an average of 198 days. Incubation periods were shorter as observed in all eggs laid by FI and FII females than the eggs of FIII female.

A significant difference was observed in incubation periods of different clutches of a season. Longer incubation period $(\mathrm{n}=$ $13 ; \mathrm{x}=224.6$ days) was noted in the $1^{\text {st }}$ clutch compared to incubation period of $2^{\text {nd }}$ clutch $(n=11 ; x=160$ days). Shorter incubation period was observed in the $3^{\text {rd }}$ and $4^{\text {th }}$ clutches $(n=$ $5 ; \mathrm{x}=147.8$ days). Shorter incubation periods were observed in those clutches or eggs that were laid later in a season.

During the study the hatchling success was on an average $64.53 \%$ per year, with the highest rate of success $97.3 \%$ noticed in the year of 1992-93 and lowest rate of success $30 \%$ observed in the year of 1990-91.

The female-wise average of hatchling success was $72.3 \%, 57.1 \%$ and $58.9 \%$ in the case of FI, FII and FIII females, respectively. Hatchling success between clutches showed $82.25 \%, 75.38 \%$ and $55.85 \%$ success in $3^{\text {rd }}, 2^{\text {nd }}$ and $1^{\text {st }}$ clutches respectively.

Table 3. The clutch-wise comparatives of clutch size, egg size and hatchling size of $\mathrm{G}$. elegans.

\begin{tabular}{|c|c|c|c|c|c|c|c|}
\hline FemaleID & $\begin{array}{l}\text { Average } \\
\text { clutch size }\end{array}$ & $\begin{array}{l}\text { Average egg } \\
\text { size }(\mathrm{mm})\end{array}$ & $\begin{array}{l}\text { Average egg } \\
\text { weight }(\mathrm{mm})\end{array}$ & $\begin{array}{l}\text { Average size of hatchlings } \\
(\mathrm{mm}) \mathrm{CL} \times \mathrm{CW} \times \mathrm{PL} \times \mathrm{H}\end{array}$ & $\begin{array}{l}\text { Average } \\
\text { weight of } \\
\text { hatchling (g) }\end{array}$ & $\begin{array}{l}\text { Numbers } \\
\text { of hatchling } \\
\text { success }\end{array}$ & $\begin{array}{l}\% \text { Of } \\
\text { success }\end{array}$ \\
\hline \multicolumn{8}{|l|}{$1^{\text {sT }}$ Clutch } \\
\hline F I & 6.42 & $37.9 \times 33.9$ & 24.64 & $38.5 \times 35.5 \times 31.6 \times 24.9$ & 16.10 & 28 & 66.66 \\
\hline F II & 4.57 & $41.2 \times 32.5$ & 24.14 & $35.9 \times 35.7 \times 32.7 \times 24.6$ & 15.25 & 15 & 46.87 \\
\hline F W & 4.80 & $44.4 \times 34.5$ & 36.14 & $43.1 \times 41.7 \times 38.3 \times 27.3$ & 24.75 & 20 & 58.82 \\
\hline Average & 5.26 & $41.1 \times 34.5$ & 28.30 & $38.2 \times 37.6 \times 34.2 \times 25.5$ & 18.70 & 63 & 57.45 \\
\hline \multicolumn{8}{|l|}{$2^{\text {nd }}$ Clutch } \\
\hline F I & 5.83 & $37.8 \times 33.5$ & 23.83 & $37.4 \times 37.3 \times 33.3 \times 25.4$ & 16.44 & 28 & 80.00 \\
\hline F II & 5.00 & $41.9 \times 32.8$ & 23.70 & $36.3 \times 36.0 \times 32.7 \times 24.6$ & 15.25 & 18 & 72.00 \\
\hline F W & 5.00 & $44.0 \times 33.0$ & 35.00 & $41.6 \times 39.2 \times 34.8 \times 26.5$ & 21.50 & 03 & 60.00 \\
\hline Average & 5.27 & $41.2 \times 33.1$ & 27.51 & $38.4 \times 37.533 .6 \times 25.5$ & 17.33 & 49 & 75.38 \\
\hline \multicolumn{8}{|l|}{$3^{\text {rd }}$ Clutch } \\
\hline F I & 4.50 & $38.3 \times 34.0$ & 23.50 & $37.6 \times 37.3 \times 35.5 \times 25.3$ & 16.75 & 07 & 77.77 \\
\hline F II & 4.00 & $41.0 \times 33.4$ & 23.00 & $34.4 \times 34.8 \times 27.4 \times 23.4$ & 14.15 & 07 & 87.50 \\
\hline F W & 0.00 & $--\quad \quad--$ & - & - & - & - & -- \\
\hline Average & 4.25 & $39.6 \times 33.7$ & 23.25 & $36.0 \times 36.0 \times 31.4 \times 24.3$ & 15.14 & 14 & 82.35 \\
\hline \multicolumn{8}{|l|}{$4^{\text {th }}$ Clutch } \\
\hline F I & 5.00 & $39.3 \times 33.6$ & 25.00 & $38.2 \times 38.2 \times 34.7 \times 25.7$ & 16.00 & 5 & 100 \\
\hline F II & 5.00 & $44.0 \times 31.7$ & 23.00 & - & - & - & 000 \\
\hline F W & 0.00 & -- & - & - & - & - & -- \\
\hline Average & 5.00 & $41.6 \times 32.6$ & 24.00 & $38.2 \times 38.2 \times 34.7 \times 25.7$ & 16.00 & 5 & 50.00 \\
\hline
\end{tabular}

$\mathrm{CL}$ - carapace length; CW - carapace width; PL - plastron length: $\mathrm{H}$ - height; $\mathrm{W}$ - weight. 


\section{Hatching season and hatchlings size}

The hatching season was recorded from mid-June to July. $97.70 \%$ hatchlings emerged in mid June after the first heavy shower of the season.

Size of hatchlings varied from $30.0(\mathrm{CL}) \times 31.5(\mathrm{CW}) \times 28.0(\mathrm{PL})$ x $22.5(\mathrm{H}) \mathrm{mm}$ with $10.50 \mathrm{~g}$ weight to $51.0(\mathrm{CL}) \mathrm{x} 45.3(\mathrm{CW}) \mathrm{x} 47.0$ $(\mathrm{PL}) \times 30.0(\mathrm{H}) \mathrm{mm}$ and $33.0 \mathrm{~g}$ weight. A total of 131 hatchlings were measured, with an average of $38.4(\mathrm{CL}) \times 37.7(\mathrm{CW}) \times 34.2$ (PL) x $25.6(\mathrm{H}) \mathrm{mm}$ size and $18.47 \mathrm{~g}$ weight.

Noticeable differences were observed in the size of the hatchlings. The hatchlings from eggs laid in the first clutch of the season were larger and heavier than the hatchlings from second and third clutches. The hatchling size and weight (average) gradually reduced when the female laid multiple clutches in a breeding season, except hatchlings from the $4^{\text {th }}$ clutch (see: Table 3). Hatchling size was related to size of laid eggs: larger hatchlings emerging from larger eggs.

\section{Temperature and breeding season}

Ambient temperatures (max. and min.) play an important role in a breeding season (Fig. 3). Mating season of the species was observed from second half of June to March with diurnal temperatures recorded between $30^{\circ}$ to $36^{\circ} \mathrm{C}$ during the months. As the temperature raised to $37^{\circ} \mathrm{C}$ upward during the months of April to first half of June all activities stopped, except foraging. Nesting activity was recorded from October to March during the cooler months. April to first half of June is summer when days are longer than the night, which seems to be the best time for incubation. The species preferred June (second half) to March when temperatures do not exceed $36^{\circ} \mathrm{C}$. Monsoon plays a vital role in IST breeding. First heavy showers of season initiate the reproductive activity and probably induce the emergence of hatchlings from the eggs.

\section{Discussion}

During the study, breeding activity of Geochelone elegans was observed round the year, with courtship in June to emergence of the hatchlings in June next (rarely extended up to July). This strongly supports that the breeding season of the species coincides with the monsoon and this corroborates with earlier studies (Hutton, 1837; Minton, 1966; Frazier, 1987; Das, 1995).

Nesting activity was observed for six months from October to March, which matches with observations of Das (1991).

Clutch size in present study is an average of 5.13 with 1.85 clutches per year and the range of 2 to 10 eggs, which supports observations of earlier workers (Table 4). Laying of more than two or multiple clutches by the species has been recorded earlier by Deryaniyagala (1939), Whelan \& Coakley (1982) and Grigus (1998), with report of even five clutches in captive populations.

During present study it was noticed that the eggs were laid during different months from October to March but hatchlings emerged only June (128 eggs: 63\%) and July (only 3 eggs: 1\%) with an average incubation of 198 days (range: 107-257). All the hatchlings emerged with the heavy first showers of the season. The hatchlings emergence during rains is supported by earlier observation of Jayakar and Spurway (1966), and Frazier (1987). This strategy of emergence of hatchlings with rains is the most favorable for availability of water and food (also, during the study it was noticed that adult tortoises ate millipedes in the rainy season, which were naturally found in the cage.

The longer incubation of 257 days is quite noticeable and is longer than the earlier report of 223 days by Frazier (1987) at Junagadh, Saurashtra, Gujarat. However longer incubation periods are reported in two other species of Geochelone. The incubation period of 14 to 15 months has been recorded in $G$. chilensis (Auffenberg, 1969; Walker, 1989) and 8-18 months in G. pardalis (Archer, 1948).

The variation in incubation (107 to 257 days) during the present study might be due to environmental condition of the area and multiple clutches laid by the females in the study. The incubation period was longer in those eggs that were laid earlier in the

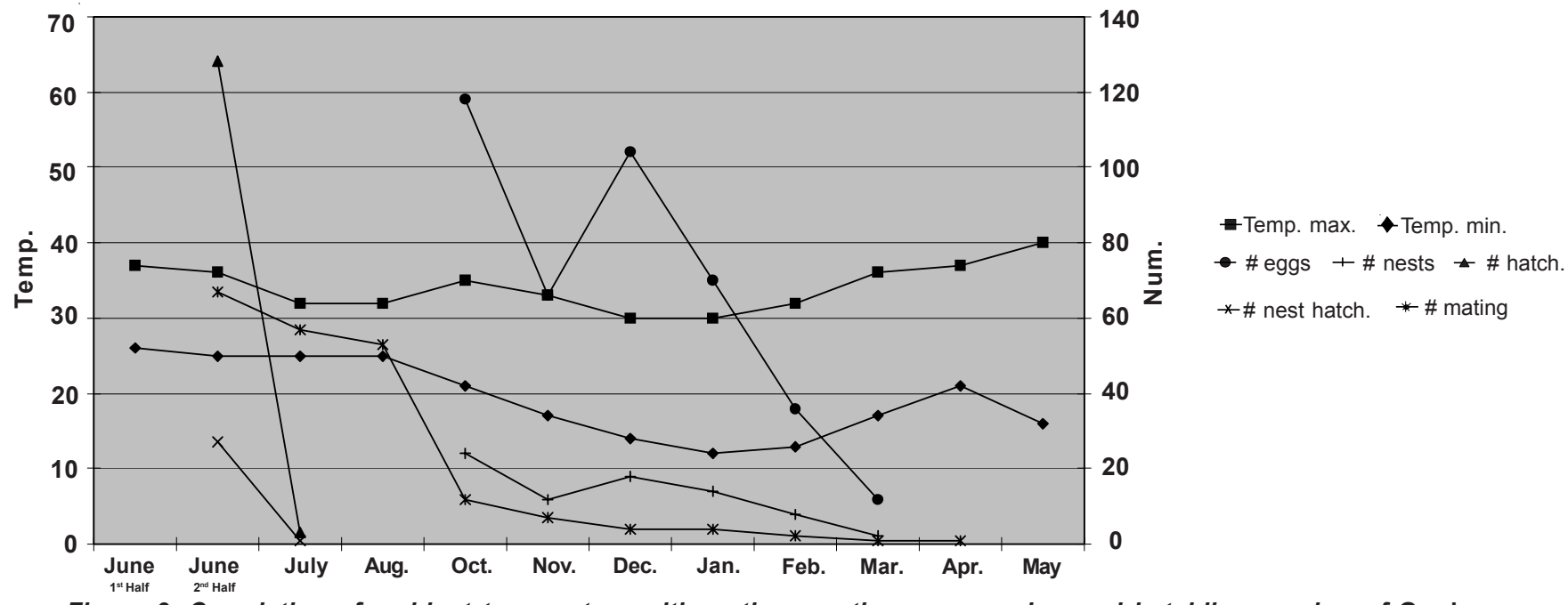

Figure 3. Correlation of ambient temperature with mating, nesting, egg number and hatchling number of G. elegans 
Table 4. A comparative statement of breeding data of G. elegans from various past and present studies.

\begin{tabular}{|c|c|c|c|c|c|}
\hline No. & Source & $\begin{array}{l}\text { Area of the study } \\
\text { size }\end{array}$ & $\begin{array}{l}\text { Clutch } \\
\text { recorded annua }\end{array}$ & $\begin{array}{l}\text { Maximum size } \\
\text { sally }\end{array}$ & $\begin{array}{l}\text { Incubation period } \\
\text { of clutches (in days) }\end{array}$ \\
\hline 1 & Deraniyagala, 1939 & Sri Lanka & $2-10$ & $2-3$ & \\
\hline 2 & Jayakar \& Spurway, 1964 \& 1966 & Buveneshwar, Orrisa & $1-7$ & & $47 \& 147$ \\
\hline 3 & Kirsche, 1976 & Barlin & $1-3$ & & $174-178$ \\
\hline 4 & Whealn \& Coakley, 1982 & N. America & $2-10$ & $3-4$ & $113-127$ \\
\hline 5 & Thulsi Rao \& Subba Rao, 1990 & $\begin{array}{l}\text { Visakhapatnam, } \\
\text { Andhra Pradesh }\end{array}$ & $2-4$ & 2 & $\begin{array}{l}112-115 \text { natural } \\
166-171 \text { in lab. }\end{array}$ \\
\hline 6 & Fraizer, 1987 & Saurashtra & 4-6 & 2 & 223 \\
\hline 7 & Grigus, 1998 & N. America & $2-9$ & $3-5$ & $84-166$ \\
\hline 8 & Daniel, 2002 & - & $3-7$ & 2 & $47-147$ \\
\hline 9 & Jagannadha Rao, 1995 & Chennai & $6-6$ & & $119-125$ \\
\hline 10 & Present study & Gujarat & $2-10$ & $3-4$ & $107-257$ \\
\hline
\end{tabular}

season in comparison to those laid later in season. This could be due to the higher ambient temperatures later in the season and comparatively smaller size of eggs in later clutches.

Record of longer incubation period in the study also might be due to delay in emergence of hatchlings. It may be the cause of death of 16 (7.88\%) fully developed embryos in the nests during the study. Also, the present experience supports the statements and conclusion of Frazier (1987) that "However, it is also possible that the full term embryos pip but wait for some environmental cue to begin digging out of the nest. In this case, the delay between hatching and emergence could be weeks or months".

A total of 131 hatchlings were successfully obtained out of 203 eggs. Forty-seven (23\%) eggs were not successfully hatched, not a negligible number. This could be due to the following possibilities: 1) eggs were infertile, 2) embryos died in the initial stage, 3) predation by ants, and 4) due to damage caused while handling the eggs for measurements. Nine $(4.43 \%)$ eggs were found damaged, five of them (of FII female) were damaged by FIII female during the digging of trial nest pit; three eggs were found broken in the nest and might have been broken by the mother (FIII) during egg laying, shifting and burying of eggs and one egg was damaged by vernier callipers.

\section{Conclusion}

The breeding season of the species starts with monsoon months June and July, courtship and mating during monsoon up to winter. They nest in winter and hatchlings of the species emerge with rains. The breeding season of the species coincides with monsoon.

Present study shows a strong correlation between the size of eggs and period of incubation. The eggs from first clutches are always larger and heavier than the eggs from second, third and forth clutch in a season. Also, it is noticed that size and weight of eggs corresponded to size and weight of hatchlings. This positive correlation of egg size and hatchlings size suggests that detailed study on western and southern population of IST should be undertaken because these two populations are recognized based on colour form and over all comparative body size.

Indian Star Tortoise (G. elegans) is highly dependent on the environmental conditions of the area and its breeding season tunes with monsoon in the area. The trend of egg laying and number of clutches was not similar in every breeding season during the study.

\section{REFERENCES}

Archer, W.H. (1948). The mountain tortoise. African Wildlife 2(3): 74-79.

Auffenberg, W. (1969). Tortoise behavior and survival. Patterns of life series. Rand McNally \& Co., Biological Science Curriculum Study, Chicago, 38pp.

Biswas, S. and L.N. Acharjyo (1984). Observation on Geochelone elegans (Schoepff) in captivity, Orissa, India. Journal of the Bombay Natural History Society 81:707-708.

Choudhury, B.C. and S. Bhupathy (1993). Turtle trade in India, a study of tortoise and fresh water turtles. Traffic India/WWF-India, 50pp. Daniel, J.C. (2002). The Book of Indian Reptiles and Amphibians. Bombay Natural History Society/Oxford University Press, 238pp.

Das, I. (1991). Colour guide to the turtles and tortoises of the Indian Subcontinent. R and A Publishing Limited, Portished, 133pp.

Das, I. (1995). Turtles and Tortoises of India. W.W.F.-India and Oxford University Press, Bombay, 176pp.

Deraniyagala, P.E.P. (1939). The Tetrapod Reptiles of Ceylon. Vol. I. Testudinates and Crocodilians. Colombo Museum, Colombo, 412pp.

De Silva, A. (2003). The Biology of the Star Tortoise (Geochelone elegans Schoepff, 1795) in Sri Lanka Zoological Gardens, Dehiwala, Sri Lanka, 100pp.

Frazier, J. (1987). Biology and Conservation of Indian Turtles and Tortoises. Interim report to the American Institute for Indian Studies, New Delhi, 64pp.

Frazier, J. (1992). Management of tropical chelonians: Dream or nightmare? pp. 125-135. In: Singh, K.P. and J.S. Singh (Eds.). Tropical Ecosystem: Ecology and Management. Wiley Eastern Limited, New Delhi.

Grigus J.M. (1998). Preliminary results of a captive breeding program involving Geochelone elegens. Biology and Conservation of the Amphibians, Reptiles and their habitats in South Asia, pp. 171-176. Proceeding of the International conference on the Biology and Conservation of the Amphibians and Reptiles of South Asia, Sri Lanka, August 1-5, 1996 October.

Hutton, T. (1837). Geometric tortoise, Testudo geometrica. Journal of Asiatic Society Bengal 6: 689-696.

Jagannadha Rao, M. (1995). Breeding behavior of starred tortoise (Gechelone elegans) at Arignar Anna Zoological Park. Zoos' Print 10(7): 30-32.

Jayakar, S.K. and H. Srupway (1964). Bimodality of laying, hatching times, Testudo elegans Schoeff (Chelonia). Nature 204: 603.

Jayakar, S.K. and H. Spurway (1966). Contribution to the biology of the Indian stared tortoise, Testudo elegans Schoepff. Journal of the Bombay Natural History Society 63: 83-114.

Kirsche, W. (1976). Beitrag zur biologie der Sternschildkrote (Testudo 
elegans Schoepff). Zoology Gart. Jena 46(1-2): 66-81. (In German). Minton, S.A. (1966). A contribution to the herpetology of West Pakistan. Bulletin of American Museum of Natural History 134: $27-$ 184.

Thulsi Rao, K. and M.V. Subba Rao (1990). Incubation and hatching of the Indian Star Tortoise Geochelone elegans in captivity. Journal of the Bombay Natural History Society 87: 461- 462.

Walker, P. (1989). Geochelone chilensis Chaco Tortoise, pp. 20-21. In: Swingland, I.R. and M.W. Klemens (eds.). The Conservation Biology of Tortoises. Occasional papers of the IUCN SSC No. 5.

Whelan, J.P. and J. Coakly (1982). Geochelone elegans (Indian Star Tortoise): Fecundity. Herpetology Review 13(3): 97.
Whelan, J.P. and J. Coakly (1985). Husbandry and breeding of the Star Tortoise Geochelone elegans, pp. 85-90. Proceedings of the $8^{\text {th }}$ Annual International Herpetology Symposium Captive Propagation and Husbandry, Columbus.

Whitaker, R. (1974). Feeding habits of the Star Tortoise. Journal of the Bombay Natural History Society 71(1): 147-148.

\section{ACKNowledgement}

I am very thankful to Mr. V. A. Jadeja, Curator, Sayaji Baug Zoo, Vadodara, India for providing facilities, and to Mr. M.A. Mehta and Pranav Trivedi for reading an earlier draft of the manuscript and comments.

Appendix 1. Season-wise breeding data of three captive females of Indian Star Tortoise (Geochelone elegans) at Sayaji Baug Zoo, Vadodara, Gujarat (1990-1997).

\begin{tabular}{|c|c|c|c|c|c|c|c|c|c|}
\hline Season & No & Female & $\begin{array}{l}\text { Date of } \\
\text { egg } \\
\text { laying }\end{array}$ & $\begin{array}{l}\text { Clutch } \\
\text { size } \\
\text { (broken) }\end{array}$ & $\begin{array}{l}\text { Average Eggs size } \\
\text { Length } \mathrm{x} \text { Width } \mathrm{x} \\
\text { Length }\end{array}$ & $\begin{array}{l}\text { No. of } \\
\text { hatchlings }\end{array}$ & $\begin{array}{l}\text { Average hatchling Size } \\
\text { CL x CW x PL x H x W } \\
\text { (succ. \%) }\end{array}$ & $\begin{array}{l}\text { Date of } \\
\text { hatching }\end{array}$ & $\begin{array}{l}\text { Incubation } \\
\text { Period }\end{array}$ \\
\hline \multirow[t]{3}{*}{$90-91$} & 1 & $\mathrm{FI}$ & 15.xii.90 & 6 & $40.4 \times 34.7 \times 25.0$ & - & - & - & - \\
\hline & 2 & FIII & 28.xii.90 & $10(1)$ & $45.6 \times 38.9 \times 36.0$ & $6(66.6)$ & $42.3 \times 44.7 \times 36.2 \times 28.2 \times 25.50$ & 16.06 .91 & 180 \\
\hline & 3 & FII & 22.i.91 & 4 & $43.3 \times 31.5 \times 22.5$ & - & -- & - & - \\
\hline \multirow[t]{7}{*}{$1991-92$} & 4 & $\mathrm{FI}$ & $15 . x .91$ & 7 & $38.2 \times 34.5 \times 24.5$ & $4(85.7)$ & $37.4 \times 37.0 \times 33.3 \times 25.4 \times 16.00$ & 10.06 .92 & 240 \\
\hline & & & & & & 2 & & 11.06 .92 & 241 \\
\hline & 5 & FII & $22 . x .91$ & 3 & $41.0 \times 32.2 \times 24.0$ & $1(33.3)$ & $33.7 \times 33.5 \times 31.0 \times 23.5 \times 15.00$ & 25.06 .92 & 257 \\
\hline & 6 & FIII & $22 . x .91$ & $4(1)$ & $45.0 \times 35.4 \times 36.0$ & $1(100)$ & $49.5 \times 45.1 \times 46.1 \times 29.7 \times 30.50$ & 14.06 .92 & 236 \\
\hline & & & & & & 2 & & 16.06 .92 & 237 \\
\hline & 7 & $\mathrm{FI}$ & 22.xii.91 & 5 & $37.4 \times 32.9 \times 24.0$ & $4(80.0)$ & $38.2 \times 38.2 \times 34.7 \times 25.7 \times 15.00$ & 22.06 .92 & 184 \\
\hline & 8 & FII & 23.i.92 & 6 & $43.3 \times 31.0 \times 22.5$ & $3(50.0)$ & $38.5 \times 38.4 \times 35.9 \times 25.4 \times 15.00$ & 11.07 .92 & 170 \\
\hline \multirow[t]{9}{*}{$1992-93$} & 9 & FII & $28 . x .92$ & 5 & $41.9 \times 32.8 \times 23.0$ & $1(100)$ & $37.1 \times 37.1 \times 35.7 \times 25.7 \times 15.00$ & 16.06 .93 & 231 \\
\hline & & & & & & 4 & & 17.06 .93 & 232 \\
\hline & 10 & $\mathrm{FI}$ & 03.xi.92 & 7 & $37.6 \times 33.9 \times 24.5$ & $7(100)$ & $34.0 \times 34.5 \times 28.5 \times 24.2 \times 15.50$ & 25.06 .93 & 233 \\
\hline & 11 & FIII & 10.xi.92 & 7 & $42.9 \times 32.2 \times 35.0$ & $7(100)$ & $39.2 \times 37.9 \times 36.3 \times 25.1 \times 21.50$ & 25.06 .93 & 226 \\
\hline & 12 & FII & 07.xii.92 & 7 & $37.9 \times 34.4 \times 23.0$ & $3(100)$ & $34.3 \times 34.2 \times 28.5 \times 24.4 \times 15.00$ & 16.06 .93 & 190 \\
\hline & & & & & & 4 & & 18.06 .93 & 192 \\
\hline & 13 & $\mathrm{FI}$ & 16.xii.92. & 7 & $36.9 \times 33.4 \times 24.0$ & $1(100)$ & $37.4 \times 37.0 \times 33.3 \times 25.4 \times 17.00$ & 19.06 .93 & 184 \\
\hline & & & & & & 6 & & 23.06 .93 & 188 \\
\hline & 14 & FIII & 01.i.93 & 5 & $44.0 \times 33.0 \times 35.0$ & $4(80.0)$ & $41.6 \times 39.2 \times 34.8 \times 26.5 \times 21.50$ & 16.06 .93 & 165 \\
\hline \multirow[t]{10}{*}{ 1993-94 } & 15 & $\mathrm{FI}$ & $25 . x .93$ & 9 & $39.3 \times 34.5 \times 24.0$ & $6(77.7)$ & $35.9 \times 35.9 \times 33.6 \times 24.2 \times 17.00$ & 17.06 .94 & 204 \\
\hline & & & & & & 1 & & 19.06 .94 & 206 \\
\hline & 16 & FII & $28 . x .93$ & 5 & $41.0 \times 32.3 \times 23.5$ & - & - & - & - \\
\hline & 17 & $\mathrm{FI}$ & 19.xi.93 & 5 & $39.4 \times 34.6 \times 24.0$ & - & - & - & - \\
\hline & 18 & FII & $26 . x i .93$ & 3 & $43.3 \times 33.2 \times 23.0$ & $3(100)$ & $35.8 \times 34.8 \times 33.6 \times 24.5 \times 15.00$ & 09.06 .94 & 195 \\
\hline & 19 & $\mathrm{FI}$ & 26.xii.93 & 3 & $38.8 \times 35.0 \times 23.5$ & $3(100)$ & $37.0 \times 36.4 \times 36.4 \times 25.0 \times 17.50$ & 22.06 .94 & 165 \\
\hline & 20 & FII & 31.xii.93 & 3 & $38.8 \times 32.6 \times 22.0$ & $2(66.6)$ & $35.0 \times 35.0 \times 27.2 \times 23.5 \times 15.00$ & 22.06 .94 & 173 \\
\hline & 21 & FIII & 26.i.94 & 2 & $38.5 \times 36.4 \times 30.0$ & - & - & - & - \\
\hline & 22 & $\mathrm{FI}$ & 04.ii.94 & 5 & $39.3 \times 33.6 \times 25.0$ & $5(100)$ & $38.2 \times 38.2 \times 34.7 \times 25.7 \times 16.00$ & 22.06 .94 & 107 \\
\hline & 23 & FII & 09.ii.94 & 5 & $44.0 \times 31.7 \times 23.0$ & - & - & - & - \\
\hline \multirow[t]{7}{*}{$1994-95$} & 24 & FIII & 10.x.94 & $4(1)$ & $44.5 \times 38.6 \times 31.0$ & $3(100)$ & $41.6 \times 39.234 .8 \times 26.5 \times 21.500$ & 19.06.95 & 244 \\
\hline & 25 & FII & $23 . x .94$ & 5 & $43.0 \times 32.9 \times 25.0$ & $3(60.0)$ & $36.0 \times 35.8 \times 31.8 \times 24.1 \times 15.00$ & 19.06 .95 & 239 \\
\hline & 26 & $\mathrm{FI}$ & 03.xi.94 & 6 & $38.4 \times 33.3 \times 24.0$ & - & - & - & - \\
\hline & 27 & FII & 22.xi.94 & 5 & $43.3 \times 33.1 \times 24.0$ & $5(100)$ & $36.7 \times 36.6 \times 32.9 \times 24.2 \times 15.50$ & 19.06 .95 & 209 \\
\hline & 28 & FII & 22.xii.94 & 5 & $43.3 \times 34.2 \times 22.0$ & $5(100)$ & $34.7 \times 34.6 \times 27.7 \times 23.4 \times 13.30$ & 19.06 .95 & 179 \\
\hline & 29 & $\mathrm{FI}$ & $30 . i .95$ & 6 & $36.1 \times 33.3 \times 22.0$ & $6(100)$ & $36.8 \times 36.5 \times 32.3 \times 25.3 \times 16.50$ & 26.06 .95 & 151 \\
\hline & 30 & $\mathrm{FI}$ & 06.iii.95 & 6 & $37.9 \times 33.0 \times 23.4$ & $4(66.6)$ & $38.2 \times 38.2 \times 34.7 \times 25.7 \times 16.00$ & 26.06 .95 & 115 \\
\hline \multirow[t]{6}{*}{$1995-96$} & 31 & FIII & 13.x.95 & 4 & $48.2 \times 41.3 \times 47.5$ & - & - & - & - \\
\hline & 32 & $\mathrm{FI}$ & 19.x.95 & 4 & $38.8 \times 33.8 \times 25.5$ & $2(75.0)$ & $35.5 \times 33.7 \times 30.5 \times 25.8 \times 15.00$ & 03.06 .96 & 228 \\
\hline & & & & & & 1 & & 06.06 .96 & 231 \\
\hline & 33 & FII & 19.x.95 & 6 & $34.8 \times 33.1 \times 25.0$ & $6(100)$ & $36.8 \times 36.5 \times 32.3 \times 25.3 \times 16.00$ & 03.06 .96 & 228 \\
\hline & 34 & $\mathrm{FI}$ & 01.i.96 & 8 & $38.7 \times 33.5 \times 24.0$ & $7(87.5)$ & $36.5 \times 36.8 \times 32.2 \times 24.9 \times 16.20$ & 03.06 .96 & 154 \\
\hline & 35 & FII & 20.i.96 & 4 & $42.0 \times 32.7 \times 26.0$ & - & - & - & - \\
\hline \multirow[t]{5}{*}{$1996-97$} & 36 & FIII & $19 . x .96$ & 3 & $46.7 \times 37.9 \times 37.5$ & - & - & - & - \\
\hline & 37 & $\mathrm{FI}$ & 25.xii.96 & 6 & $38.0 \times 33.0 \times 25.0$ & $5(83.3)$ & $36.5 \times 36.8 \times 32.2 \times 25.0 \times 17.00$ & 15.06 .97 & 172 \\
\hline & 38 & FII & 02.ii.97 & 4 & $42.0 \times 33.0 \times 26.0$ & - & - & - & - \\
\hline & 39 & $\mathrm{FI}$ & $06 . i i .97$ & 4 & $38.5 \times 33.5 \times 25.0$ & $4(100)$ & $38.2 \times 38.2 \times 34.0 \times 25.8 \times 17.00$ & 15.06 .97 & 129 \\
\hline & 39 & & & $203(3)$ & $x=41.4 \times 34.4 \times 27.93$ & 131 & $x=37.9 \times 37.5 \times 33.4 \times 25.2 \times 17.25$ & & $X=198$ \\
\hline
\end{tabular}

